\title{
Technological effectiveness of modern education: features, traditions, innovations
}

\author{
Olga Gukalenko ${ }^{*}$, Vladimir Borisenkov ${ }^{2}$, Vasiliy Kuznetsov ${ }^{2}$, Liubov Panova ${ }^{2}$, and Liubov \\ Tkach $^{3}$ \\ ${ }^{1}$ Russian Academy of Education, 119121, Moscow, Russia \\ ${ }^{2}$ Lomonosov Moscow State University, 119991, Moscow, Russia \\ ${ }^{3}$ Transnistrian State University named after T.G. Shevchenko, 3300, Tiraspol, Moldova
}

\begin{abstract}
The purpose of the study is to analyze the experience in organizing the learning process at a university using digital technologies, aimed at realizing the content of pedagogical education in the context of its structural components and indicators of students' readiness to work in an educational institution. The positive and negative aspects of the use of IT-technologies in the formation of the experience of professional and pedagogical activities of students in the direction of "Pedagogical education" are noted. The relevance of using digital technologies in the educational process is dictated by the prevailing socio-cultural conditions, the development of information and communication means of transmission and information. At the same time, the problem is the unwillingness of the faculty, students, to their use for several reasons: news, illiteracy, lack of equipment in detail-spatial environment of technical means, the quality of Internet connection. And technologies which provide ability to save dialogicality pedagogical culture, allowing to establish a dialogue in the systems "teacher-student", "student-teacher" and the polylogue "student-teacher-students" are particularly in demand. The use of the technology "Immersion in professional and pedagogical activity through culture with the support of the teacher" allows the teacher to conduct a dialogue with students and purposefully form their readiness for pedagogical activity in modern conditions based on the acceptance of the values of pedagogical culture and identification in her, personal and semantic attitude to labor functions for the provision of educational services for the main educational programs of educational organizations of different levels.
\end{abstract}

\section{Introduction}

An important task of preparing a teacher for activity in modern conditions is the formation of a number of competencies, which are defined in the Federal State Educational Standard of Higher Education in the pedagogical direction and in the professional standard of the teacher. The priority qualities of a trained teacher are based on mastery of organizational skills, adherence to humanistic values and experience in information

\footnotetext{
*Corresponding author: olga_gukalenko@mail.ru
} 
activities. Of particular importance in the structure of the teacher's readiness for activity in modern conditions of dynamic changes is acquiring his ability to research, independent search, selection and continuous updating of existing knowledge, orientation to the use of various methods of adapting scientific knowledge in solving professional problems based on the use of productive educational technologies. A teacher who has the ability to innovate on the basis of a reasonable selection and use of updated technologies and is motivated for constant self-improvement is becoming in demand.

The purposeful formation of such a teacher is facilitated by the inclusion of special disciplines in the main professional educational program in the psychological and pedagogical direction, the content of which involves acquainting students with the basics of research work, digital technologies and methods of their application, for example: " Methodology and methods of scientific research", "Innovative processes in education", "Modern problems of science and education", "Modern educational technologies", "Information technologies in professional activities". But, it is necessary to distinguish the means that ensure the automation of the learning process - video lectures, videos as illustrations of the content being mastered, electronic textbooks, etc. from the digitalization of education, which involves the use of online learning and requires the creation of an interactive subject-developing environment, including online versions of educational materials, plans, classes, magazines and other documents regulating educational activities.

Various studies in the field of innovative pedagogy made it possible to identify the general and specific features of innovative activity, the role and place of the research component in it, the influence of teachers' motivational readiness on the content and quality of innovative activity and etc. Scientists have found that the nature of the course of innovation processes is determined by three interrelated forces: the characteristics of the introduced innovation, the innovative potential of innovators, the environment, as well as the characteristics of the innovative activity of the initiators and participants of the innovation [1, 2, 3].For our research, of interest are the works of scientists who reveal conceptual approaches to the design of the content of education in the context of its diversification $[4,5,6]$, presenting the results of research in the field of systematization of its substantive aspectsand optimization of the educational process [7, 8], revealing the issues of pedagogical integration in the theory and practice of education abroad [9, 10].Studies of the peculiarities of preparing teachers for professional activities show that, in addition to general subject training, it is necessary to purposefully form teachers' readiness for specific innovation and the development of abilities for innovative activities $[11,12]$.

When substantiating the technology developed by us and its implementation in the process of teacher training, we were guided by the opinion of E.V. Bondarevskayathat the adaptability of the pedagogical process is an indicator of the quality of education, and pedagogical technology is the art of teaching, focusing on a quality result[13].

When designing the multicultural content of lifelong pedagogical education, we proceed from the position that it should be similar to social experience and include the following structural elements: knowledge, the ability to act according to the model and the ability to make non-standard decisions in problem situations, personal orientations and also to wear contextual and professionally oriented, culture-like character.E.V. Bondarevskaya,in substantiating the culturological personality-oriented education, put forward a conceptual proposition that personal meanings of learning are important, not separate skills and abilities, but individual abilities, independent learning activities and personal life experience are needed. The scientist believes that content should be transferred from the level of meanings to the level of personal meanings, so that it is perceived by students as social, moral, aesthetic or some other value. In our case, this is a professional value. An obvious contradiction continues to be the objective need of a modern school for a teacher 
with a high level of culture (professional, methodological, etc.), who has a clear civic and personal position, and the real state of readiness of teachers to work in a multicultural society, which is characterized by a predominantly low and sufficient level.

\section{Materials and Methods}

The purpose of the study is to analyze the experience in organizing the learning process at a university using digital technologies, aimed at realizing the content of pedagogical education in the context of its structural components and indicators of students' readiness to work in an educational institution [14].

Number of respondents who took part in the study is 320 students.

Various methods of the study were used including literature analysis, survey, questionnaire, blitz polls, matching, graphic methods, comparison [15], review and interpretation $[16,17]$.

Our research is of a longitudinal nature. The results obtained from regularly conducted diagnostic procedures and feedback from employers indicate a fairly high level of effectiveness of the methods and techniques used for mastering the multicultural content of pedagogical education. To determine the dynamics of the results obtained, the diagnostics of the formation of the value-content, activity-creative, motivational-need components of students' readiness for pedagogical activity is used, which are characterized by the level of polycultural literacy, a creative approach to activity, a positive attitude to multicultural values and the level of motivation for pedagogical activity. Diagnostics and monitoring of the quality of readiness were carried out in accordance with a set of criteria and indicators adequate to them, using a variety of methods, which allowed to obtain reliable facts proving the effectiveness of the conditions and ways tested in the process of training a multi culturally oriented teacher who is able to carry out professional and pedagogical activities in a multicultural educational institution.

\section{Results}

Studying the cognitive activity of students, we monitored the activities of university teachers, attended classes, talked, which made it possible to identify the most frequently used factors for stimulating students' cognitive activity. In addition, we conducted a survey of students of the I, II, III courses in order to identify their attitude to the stimulating factors of educational and cognitive activity. The dynamics of changes in the attitude of students to the stimulating factors of educational and cognitive activity is presented in Table 1.

Table 1. Students' attitude.

\begin{tabular}{|l|l|l|l|}
\hline \multicolumn{1}{|c|}{ Factors } & $\begin{array}{c}\text { I course, } \\
\text { 106 people } \\
\text { 2017/18 }\end{array}$ & $\begin{array}{c}\text { II course, } \\
\text { 102 people, } \\
\text { 2018/19 }\end{array}$ & $\begin{array}{c}\text { III course, } \\
\text { 112 people, } \\
\mathbf{2 0 1 9 / 2 0}\end{array}$ \\
\hline Historical excursions & $8-7.5 \%$ & $29-28.4 \%$ & $40-35.7 \%$ \\
\hline $\begin{array}{l}\text { Cross-cultural presentation } \\
\text { educational material }\end{array}$ & $12-11.3 \%$ & $28-27.5 \%$ & $59-52.7 \%$ \\
\hline IT technologies & $10-9.4 \%$ & $36-35.2 \%$ & $48-42.9 \%$ \\
\hline $\begin{array}{l}\text { Actualization of the subject experience } \\
\text { of students }\end{array}$ & $46-43.4 \%$ & $65-63.7 \%$ & $94-83.9 \%$ \\
\hline Advanced teaching experience & $42-39.6 \%$ & $64-62.7 \%$ & $72-64.3 \%$ \\
\hline Practical significance & $26-24.5 \%$ & $50-49.0 \%$ & $79-70.5 \%$ \\
\hline
\end{tabular}


The results of the survey indicate a direct proportional dependence of the increase in interest in stimulating factors on the level of training of students and the degree of their mastery of the culture of professional and pedagogical activity.

The current use of certain digital technologies in the educational process of preparing students for pedagogical activity, stimulated by the conditions of the pandemic, has revealed a number of positive aspects. These include: the availability of educational material, the speed of feedback, the ability to repeatedly refer to the content offered for development, an increase in the level of independence, etc.

At the same time, the results of our survey of students indicate their ambiguous attitude to the organization of training using IT technologies (Zoom, Moodle platform). Full-time and part-time students mastering the "Preschool education" profile noted that the Zoom platform (86\%) is preferable for acquaintance with the lecture material, providing direct communication between the teacher and the audience and the ability to demonstrate certain provisions with various kinds of illustrations. According to the students $(48 \%)$, the Moodle platform allows you to carry out independent work on the study of the discipline assignments for practical and laboratory classes at their own pace and time without visiting an educational institution. The majority of respondents (94\%) noted the objective nature of testing organized in the Moodle system.

The opinions of teachers regarding the digitalization of pedagogical education are of a different polarity and the argument is mainly based on the complexity of mastering new technologies and the need for special training for their use.In this connection, it is reasonablyto analyze researches, revealing the peculiarities of innovative activity, since digital education is an innovation that causes controversy towards its development.

When modeling the technology "Immersion in professional pedagogical activity through culture with the support of a teacher", the activity-creative approach was defined as the fundamental one [14], providing the accumulation of subjective experience in solving professional problems in the learning process based on the combination of activities to form theoretical knowledge with the practical needs of students and the ability to selfdetermination in accordance with standard requirements.

An important condition for the development of technologies of the educational process at a university is the need to take into account such a property of pedagogical culture as its dialogicality, which necessitates the creation of a system of interaction "teacher-student" on the principles of dialogue, ensuring the formation of the subjectivity of students and the formation of their professional and pedagogical competence.

The category of "susceptibility to innovations" can act as a methodological basis in the design of technologies for mastering the content of pedagogical education by students for whom it represents a certain innovation. In the interpretation of the author of the latter is a complex stepwise thought process of making decisions about the use / failure innovations: awareness stage (initial introduction) $\rightarrow$ Interest stage (expression of interest to innovation) $\rightarrow$ Evaluation Download now stage (evaluation) $\rightarrow$ by trial stage (testing) that may result in a rejection of innovation rejection $\rightarrow$ adoption stage (final perception).

\section{Discussion}

Considering the above, we offer students a step-by-step mastering of the content of the discipline "Multicultural education" and their preparation for intermediate certification:

"Stage I. Get acquainted with the questions for the exam and prepare an essay on one of the questions (at the student's choice).

Stage II. Choose about din from the remaining questions for the exam and prepare a presentation. 
Stage III (implemented in parallel with stages I and II). It is necessary to divide into subgroups, choose a didactic project, design its content together with the teacher and work during the semester, presenting reporting materials during the current certification. Work in the project involves the transformation of students' theoretical knowledge into the necessary professionally significant skills and abilities, with the help of which they will be able to implement the leading ideas of the discipline in the pedagogical process of educational institutions, taking into account the regional characteristics of society.The development of the content of the disciplines of the artistic and aesthetic cycle is carried out on the basis of the theory of the stage-by-stage formation of mental actions. The presentation of the material occurs in the following sequence: practical skills in working with various materials $\square \rightarrow \square$ the concept of activities $\rightarrow$ the content and organization of artistic work of preschool children $\rightarrow$ features of the management of children's activities. Pedagogical management of students' activities is based on a differentiated approach, taking into account their subjective experience, subordinated to the tasks of developing creativity and the formation of a multicultural personality orientation.

Currently, we apply technology enriched with elements of IT -technologies that helps to activate Research Search and students, their cognitive activity and in terms of online learning, continue to work professionally significant employment skills to develop. This approach to the organization of training allows you to correctly combine traditional lectureworkshop training system with innovation - the introduction of Internet resources in the educational process. According to Russian scientists, which is based on the peculiarities of educational interactions in the system "learners-teachers-information sources", there is a third model "Student - Internet - Teacher", in which distance learning partially replaces full-time education. In the context of pedagogical education, this replacement should be expedient, correct, and professionally oriented. For example, presenting a report on the work in the project, when organizing a master class on the topic "Migratory Birds of Transnistria", demonstrating the forms of working with preschool children, they suggested a link, following which they made bullfinches using the origami technique, and then made a collective collage; on the theme "Music Salon" the game "Guess the melody" was held songs for children, a selection of which was carried out using Internet sources, etc.

Revealing the effectiveness of the use of digital technologies in combination with traditional forms of education in the process of training a multiculturally oriented teacher should be carried out on the basis of an analysis of the level of formation of the components of his readiness for professional and pedagogical activity. When compiling the characteristics of the levels of mastering the discipline (high, medium, sufficient and low), developing assessment criteria, we use the taxonomy of B. Bloom's goals.

High level - characterized by a meaningful attitude to the values of education and culture, the desire to develop personal qualities and professional and pedagogical culture. Value orientations of students at the level of their beliefs, they realize and accept multicultural values as norms of their own activities based on an assessment of their significance. Future teachers are able to explain the nature of the culture of a particular group, plan their behavior in a foreign cultural environment, form their own judgment, draw conclusions and conclusions about anti-cultural behavior and choose a multicultural line of behavior to prevent or creatively resolve conflict; speak three or more languages; understand the importance of traditions in multicultural education, are able to create and implement them in professional and pedagogical activities. Students' activities are creative; based on the analysis and assessment of the cultural situation (in a group, class), self-analysis of processes and results of activity, they strive to build a pedagogical process on the basis of subject-subject relationships with students, while showing creative activity, independence in decision-making; conduct an active research and development search. 
The middle level is characterized by stable cognitive and social activity of students. They are able to identify essential and insignificant features in the behavior and mentality of representatives of a cultural group, analyze the reasons leading to cultural conflicts, see the cultural one-sidedness or versatility of this or that phenomenon, partially understand and accept poly-cultural values as norms of their own activity, speak two languages, use folk traditions in the practice of working with children, take an active part in the development and conduct of educational affairs at the faculty. Value orientations of students at the level of ideals and aspirations. Students are proficient in algorithms for the rational construction of activities, are able to define a goal and plan their actions, and creatively implement them. The activities of future teachers are productive in nature and are associated with the modification of existing analogues.

Sufficient level - students have an inherent understanding of the psychology of a minority surrounded by the majority, they are able to interpret another culture (its symbols, patterns, traditions, clothing style, etc.), see differences and similarities between cultures, demonstrate tolerant behavior, reflect on their feelings and actions in relation to those who have differences and originality; have an idea of folk traditions, observe the traditions of the faculty, master one of the official languages, but at the same time do not experience a steady aspiration for cultural self-development; understand the significance of multicultural values, but do not understand them as norms of their own activities. Students are familiar with various approaches in education and the structure of pedagogical activity, they are guided in a changing situation, they are able to perform a complete technological process, apply theoretical knowledge to solve practical problems, but the performance of the activity is reproductive in nature; believe that their cultural and professional growth is possible and will be determined by the time and length of service.

Low level - the future teacher possesses theoretical and methodological training in the specialty, is satisfied with the existing level of development of professional and pedagogical culture, has fragmentary knowledge about the methodology of the activity approach, is focused on establishing subject-object relations with students; has an idea of the concepts: culture, cultural and multicultural identity of a person, prejudice, tolerance, acceptance, respect, ethnicity, but does not consider it important for himself to assign multicultural values as norms of his own life; knows the peculiarities of the cultures of the peoples of the region, knows only one language, does not strive for cultural creativity. The student's activity is of a performing nature (value-oriented, cognitive, goal-setting components are minimized), i.e. he is capable to perform individual technological operations. For the purpose of compact presentation of the results of diagnostics and monitoring, their comparative analysis at the ascertaining and final stages of the experiment, we use the dynamics of integrative characteristics: multicultural literacy, creative approach to activity, attitude to multicultural values and motivation of pedagogical activity.

\section{Conclusion}

In conclusion, it can be stated that modern challenges and problems caused by the ongoing changes actualize the need to search for new approaches to pedagogical education of future teachers based on the implementation of practice-oriented learning. The modern understanding of education allows us to characterize it as a process that determines not only the significance of the knowledge aspect, but also provides conditions for free selfdetermination of the individual, acceptance of universal human values, and the development of value self-actualization in culture and society.

In pedagogical science, the problem of preparing a teacher for professional pedagogical activity always remains not fully resolved due to changing socio-cultural conditions and 
requirements for his personal and professional qualities. Currently, educational science and practice is looking for conditions, means, content that are adequate to the situation and development prospects, ensuring the readiness of a university graduate for professional and pedagogical activity on the basis of a personal and semantic understanding of its priorities in the context of informatization of social development, which implies in the design of the content of pedagogical education and technologies for its development, balancing a variety of information flows and interactive educational platforms in the spatial educational environment of the university.

\section{References}

1. A. Belousova, U. Mochalova, Behavioral Sciences 10 (3), 68 (2020). DOI: 10.3390/bs10030068.

2. A. Belousova, V. Pishchik, Engineering and Education (IJCRSEE) 3 (2), 1-8 (2015).

3. S. Bloemeke, U. Suhl, Journal of teacher education 62 (2), 154-171 (2011). DOI: $10.1177 / 0022487110386798$.

4. V. Borisenkov, O. Gukalenko, V. Kazarenkov, T. Kazarenkova, et al., E3S Web of Conferences 210, 18063 (2020).

5. O. Fedotova, V. Latun, Yu. Merinova, A. Ertel, E3S Web of Conferences, INTERAGROMASH 2020 175, (2020). DOI: 10.1051/e3sconf/202017515026.

6. V. Bond, Journal of music teacher education, 1057083721993738 (2021). DOI: $10.1177 / 1057083721993738$.

7. V. Borisenkov, V.P. Borisenkov, A. Zapesotskii, N.N. Malofeev et al., Russian Education and Society 49 (2), 54-69 (2007).

8. P. Youhasan, Y. Chen, M. Lyndon, M. Henning, BMC nursing 20 (1), 50 (2021). DOI: $10.1186 / \mathrm{s} 12912-021$.

9. J. Koenig, S. Klemenz, Zeitschrift fur Erziehungswissenschaft 8 (2), 247-277 (2015). DOI: 10.1007/s11618-015-0623-9.

10. O. Fedotova, V. Latun, Mediterranean Journal of Social Sciences 6 (4), 356-361 (2015). DOI: 10.5901/mjss.2015.v6n4p356.

11. V.P. Borisenkov, O.V. Gukalenko, L.T. Tkach, European proceedings of social and behavioural sciences. Dialogue of cultures - culture of dialogue: from conflicting to understanding, 184-189 (2020). European Publisher, London.

12. C. Tulbure, Procedia - Social and Behavioral Sciences 76, 832-836 (2013).

13. E.V. Bondarevskaya, Higher education in Russia 1, 74-80 (2014).

14. V.P. Borisenkov, Russian Education and Society 49 (1), 60-77 (2007).

15. O. Fedotova, O. Chigisheva, International Perspectives on Education and Society 26, 57-82 (2015). DOI: 10.1108/S1479-367920140000026003.

16. L. Cohen, L. Manion, K. Morrison, Research methods in education $6^{\text {th }}$ edition (Routledge, London and New York, 2008).

17. J. Freeman, M. Walters, J. Campbell, How to display data (Bleckwell Publishing, Oxford, 2008). 